\title{
EFFECT OF R, $\mu$ AND T ON THE FRAGILITY CURVES FOR TWO SPANS REINFORCED CONCRETE HIGHWAY BRIDGES
}

\author{
KARIMI F. ${ }^{\text {a,* }}$, RANJBARAN A. ${ }^{\text {b }}$, AMIRIAN P. ${ }^{\text {c }}$ \\ ${ }^{a},{ }^{*}$ Shiraz University, Department of Civil and Environmental Engineering, Shiraz, Iran, e-mail: f.karimi@ shirazu.ac.ir \\ ${ }^{\mathrm{b}}$ Shiraz University, Department of Civil and Environmental Engineering, Shiraz, Iran, e-mail: ranjbarn@ shirazu.ac.ir \\ ${ }^{c}$ Shiraz University, Department of Civil and Environmental Engineering, Shiraz, Iran, e-mail: pamirian@shirazu.ac.ir
}

Received: 11.07.2019 / Accepted: 31.08.2019/ Revised: 11.10.2019 / Available online: 10.12.2019

DOI: 10.2478/jaes-2019-0020

KEY WORDS: Bridge, Fragility, Force reduction factor, Path method, Opensees.

\begin{abstract}
:
Fragility curves are useful tools for evaluating the probability of structural damage due to earthquakes as a function of ground motion indices. The force reduction factor $(\mathrm{R})$ is one of the seismic design parameters that determine the nonlinear performance of building structures during strong earthquakes. $\mathrm{R}$ factor itself is mostly a function of displacement ductility $(\mu)$, natural period of a structure, and soil conditions. A statistical method (Path Analysis) is proposed for the first time to determine the effect of R, $\mu$ and T on the column fragility curve parameters of typical box girder, two spans reinforced concrete highway bridge class. An analytical approach was adopted to develop the fragility curves based on numerical simulation. The $\mathrm{R}, \mu$ and fundamental period $\mathrm{T}$ have been used to characterize different bridge configurations. The total, direct, and indirect effects of the variables as having significant effect on fragility curve parameters were identified.
\end{abstract}

\section{INTRODUCTION}

Bridges are potentially one of the most seismically vulnerable structures in the highway system during earthquake events. Bridges damaged by an earthquake can threaten immediate recovery efforts and cause large economic losses.

Support for this recovery effort and loss estimation can be typically achieved via the use of damage functions of structures (called fragility curves) (Kircher et al. 2006). For a structural component or system of interest, seismic fragility represents the probability that the demand imposed by earthquake loading will exceed a prescribed threshold, conditioned on a measure of ground motion intensity. The notion of fragility has been used widely to convey probabilistic information on seismic related damage (e.g., Kennedy \& Ravindra 1984, Singhal \& Kiremidjian 1996, Straub \& Der Kiureghian 2008). Empirical fragility curves are developed using actual damage information from past earthquakes, whereas analytical fragility studies have been performed using demands obtained from capacity spectra or time history analyses. For the most part, damage states addressed by analytical bridge fragility studies were those used to describe empirical bridge fragilities, often defined in terms of deformation or ductility based discrete demand quantities. Various researchers (Choi et al. 2004); (Mackie and Stojadinović 2005); (Ramanathan et al. 2010); (Jeong and Elnashai 2007); (Nielson 2005); (Padgett et al. 2008) have developed the fragility curves for bridge structures. Fragility curves can be utilized to demonstrate when a coefficient or a number of parameters are used to improve the performance level of a structure.

Seismic codes rely on reserve strength and ductility, which improves the capability of the structure to absorb and dissipate energy. Hence, the role of the force reduction factor and the parameters influencing its evaluation and control are essential elements of seismic design according to codes. The force reduction factor $(\mathrm{R})$ is one of the seismic design parameters that determine the nonlinear performance of building structures during strong earthquakes. R-factor itself is mostly a function of displacement ductility $(\mu)$, the natural period of a structure $(T)$, and soil conditions (Miranda). The $\mathrm{R}$ factor is defined as the ratio of the force required for the system to remain elastic $F_{\text {el }}$ to the yield force of the inelastic system $F_{Y}$

$$
R=\frac{F_{e l}}{F_{Y}}=\frac{s a_{\varepsilon l}}{A_{y}}
$$

Using a single-degree-of-freedom system approximation and canceling the equivalent mass of the bridge, the $\mathrm{R}$ factor can be stated in terms of accelerations, where the elastic pseudospectral acceleration response ordinate at the bridge period is $\mathrm{Sa}_{\mathrm{el}}$ and the structural yield acceleration is $A_{Y}$.

In this paper a statistical method (Path Analysis) is proposed for the first time to determine the effect of $\mathrm{R}, \mu$ and $\mathrm{T}$ on the

\footnotetext{
* Corresponding Author: Karimi F., phone number: +989131451377, e-mail: f.karimi@ shirazu.ac.ir
} 
fragility curve parameters of typical box girder, two spans reinforced concrete highway bridge class that provides a consistent treatment of uncertainties in both demand and capacity estimates. Sophisticated finite element models and nonlinear time history analysis are used to define demand. Common to all of the bridges are two spans, continuous reinforced concrete box girder superstructure, single and multicolumn bent with uniform circular cross section over the entire column height above grade. The portfolio of bridges was further limited to those with two equal spans on each side of the column bent and seat type abutments. A suite of bridges was generated by varying certain design parameters within acceptable engineering ranges using Latin Hypercube Sampling (LHS) (McKay et al. 2000). LHS provides an effective scheme to cover the probability space of the random variables when compared to pure random sampling using naïve Monte Carlo Simulation (Celik and Ellingwood 2010).

\section{PATH METHOD}

In statistics, path analysis is used to describe the directed dependencies among a set of variables. This includes models equivalent to any form of multiple regression analysis, factor analysis, canonical correlation analysis, discriminant analysis, as well as more general families of models in the multivariate analysis of variance and covariance analyses (MANOVA, ANOVA, ANCOVA). Path analysis was originally developed by geneticist Wright (1920) to examine the effects of hypothesized models in phylogenetic studies. Wrights analysis involved writing a system of equations based on the correlations among variables influencing the outcome and then solving for the unknown parameters in the model (Land 1969). According to Wright, the path analytic method was intended to measure the direct effect along each separate path in such a system and finding the degree to which variation of a given effect is determined by each particular cause. Path analysis is a statistical technique used primarily to examine the comparative strength of direct and indirect relationship among variables. Path analysis consists of a family of models that depicts the influence of a set of variables on one another. It is considered closely related to multiple regression analysis. It is an extension of the regression models, which researchers use to test the fit of a correlation matrix with a causal model that they test (Alwin and Hauser 1975). The aim of path analysis is to provide estimates of the magnitude and significance of hypothesized causal connections between sets of variables displayed through the use of path diagram. Since path analysis assesses the comparative strength of different effects on an outcome, the relationship between variables in the path model are expressed in terms of correlations and represent hypotheses proposed by the researcher. However, path models do reflect theories about causation and can inform the researcher as to which hypothesized causal model best fit the pattern of correlations found within the data set. One of the advantages of path analysis is that it forces researcher to explicitly specify how the variables relate to one another and thus encourages the development of clear and logical theories about the process influencing a particular outcome.

\subsection{The fundamental assumption}

Let us consider a finite number of standardized random variables arranged in a historical or logical sequencedistinguishing antecedent, contemporary, and subsequent (dependent) variables. Wright (1920) has shown that three assumptions are sufficient to justify the basic equation of path analysis. (1) unitary factors: all variables are treated as unitary factors, so that one part of a composite variable is not more significant in one relation than another; (2) linearity: the relationships among these unitary factors are linear so that equal changes in an antecedent variable in different parts of its range are associated with equal changes in its dependent effects; (3) complete additivity: each dependent variable is completely determined by the sum of the effects of proximate antecedent variables. That is

$$
X_{i}=r_{i 1} X_{1}+r_{i 2} X_{2}++r_{i R} X_{R}=\sum_{k i}^{R}=1 r_{i R} X_{R}
$$

In above equation the $r_{i k}$ are called path coefficients, which are standardized partial linear regression coefficients. They are represented in the diagrams as a single headed arrow pointing from the antecedent variable $X_{k}$ toward the dependent variable $\mathrm{X}_{\mathrm{k}}\left(\mathrm{X}_{\mathrm{i}} \leftarrow \mathrm{X}_{\mathrm{k}}\right)$. The $\mathrm{X}_{\mathrm{k}}$ antecedents, where $\mathrm{k}=\{1,2, \ldots, \mathrm{K}\}$, may include a hypothetical residual variable, so that determination is formally complete. The correlation between $X_{i}$ and any other variable $\mathrm{X}_{\mathrm{j}}$ is defined as the expectation of the product of standardized variables, so

$$
p_{y}=\mathrm{E}\left(X_{j} X_{i}\right)=\mathrm{E}\left(X_{j} \sum_{k=1}^{N} \eta_{k} X_{k}\right)=\sum_{k=1}^{N} \eta_{k} p_{j k}
$$

This equation is Wright's fundamental equation and shows that any correlation $\mathrm{p}_{\mathrm{ij}}$ may be decomposed as the sum of products of paths to $X_{i}$ and correlations $\mathrm{p}_{\mathrm{jk}}$ among the antecedents $\mathrm{X}_{\mathrm{k}}$ and the variable $X_{j}$.

\subsection{Goodness of fit criteria}

Statistical methods normally utilize one statistical test to determine the significance of the analysis. The Path analysis, however, relies on several statistical tests to determine the adequacy of model fit to the data. For assessing the overall fit of the model, the $\chi^{2}$ values relative to the degrees of freedom are most widely calculated. This is often referred to as the chisquare test and is an absolute test of model fit. If the $p$ value associated with the $\chi 2$ value is below 0.05 , the model is rejected in an absolute fit sense. Because the $\chi 2$ goodness of fit criterion is very sensitive to sample size and non-normality of the data, often other descriptive measures of fit are used in addition to the absolute $\chi^{2}$ test. A number of goodness of fit criteria have been formulated for Path analysis.

The comparative fit index (CFI) (Bentler 1990) and root mean square error of approximation (RMSEA) (Browne and Cudeck 1993). CFI values fall between 0 and 1 , where 0 represents no fit and 1 is a perfect fit. Usually a value above 0.90 is considered acceptable, and a good fit. RMSEA incorporates the parsimony criterion and is relatively independent of sample size and number of parameters. A suggested rule of thumb for an RMSEA fit is that a value less than or equal to 0.06 indicates an adequate fit.

\section{FRAGILITY ANALYSIS}

\subsection{Probabilistic models}

The Pacific Earthquake Engineering Research PEER Center's performance-based earthquake engineering framework (Cornell 
and Krawinkler 2000) is a probability-based methodology enabling more rigorous analytical generation of damage fragility curves. The framework comprises hazard, demand, and damage models to express the conditional probability of exceeding a damage limit state using the total probability theorem.

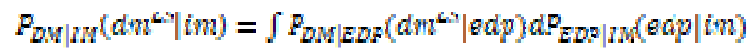

The damage fragility is the conditional probability of a damage measure $D M$ exceeding a damage limit state $\mathrm{dm}^{\mathrm{LS}}$ given an earthquake ground motion intensity measure $I M=i m$. The first term in the integrand of Eq. 4 is the cumulative distribution function $C D F$ for a damage measure $D M$ conditioned on an engineering demand parameter $E D P$, denoted the bridge damage model. The second term is the first derivative of the $C D F$ for an $E D P$ conditioned on $I M$, or simply the probability density function $P D F$ of the demand model at the specified $I M$ level.

\subsection{Demand models}

A seismic demand model describes the likely effect of earthquakes on a structure. Formally, demand models are $C D F \mathrm{~s}$ of an EDP conditioned on $I M$. Each ground motion can be described by an $I M$, the selection of which is discussed in the PEER final report (DesRoches et al. 2012) and (Luco and Cornell 2007). The IMs used in this paper are the first mode pseudo spectral acceleration with $5 \%$ viscous damping, $S a(T=1, \xi=0.05)$. These $I M$ s were chosen because demand models formulated using them have, on average, acceptably small dispersions 0.30 to 0.40 over a range of EDPs of interest for reinforced concrete highway bridges (Mackie and Stojadinovic 2004). The top displacement of the bridge column is the only EDP considered in this paper because it correlates well with bridge damage measures and with the $R$ factor used to describe the structural characteristics of the bridge.

Probabilistic Seismic Demand Models PSDM are usually formulated by means of nonlinear dynamic finite-element simulations using multiple ground motion records in a procedure called Probabilistic Seismic Demand Analysis PSDA (Mackie and Stojadinovic 2004). The resulting demand models may assume any mathematical form, but there are studious choices that simplify the evaluation of Eq. 4. A large number of demand models follow a lognormal distribution (Shome 1999); specifically, the EDP exhibits a lognormal probability distribution when conditioned on $I M$. Additionally, the dispersion $\left(\sigma_{\mathrm{EDPIIM}}\right)$ is often assumed to be constant over the range of $I M \mathrm{~s}$ considered, and a power law relationship is often used to describe the EDP in terms of the IM. Therefore, the demand model is often written as $E D F=a\left(I M^{b}\right)$. This powerlaw median relationship appears linear in log space, and linear regression can be used to obtain the unknown coefficients $A$ and $\mathrm{B}$

$$
\ln (E \hat{D} P \mid M)=A+B \ln (M M)
$$

\subsection{Damage models}

Damage models describe the likely damage induced in the structures at the level of demand sustained during an earthquake. Mathematically, damage models are $C D F \mathrm{~s}$ of $D M \mathrm{~s}$ conditioned on EDP. DMs are usually discrete, an observation of the onset of a certain limit state. It is essential that the limit state definitions use the same metric as the EDP for the respective bridge components.

Structural damage increases with increasing plastic curvatures, strain levels and displacements. In order to classify column damage slight, moderate, extensive and complete damage states (DS1, DS2, DS3, and DS4, respectively) moment curvature of each column is obtained and approximated with an idealized relationship. This relationship shall be bilinear, with initial slope and post-yield slope. The initial slope, shall be taken as the secant stiffness calculated at a moment equivalent to the first yield point. Priestly (Priestley et al. 1996) defined first yield point as the point where the outer part of tension reinforcement reaches yielding strain or the outer part of concrete fiber reaches the strain value of 0.002 . The post-yield slope shall be determined by a line segment that passes through the maximum moment of actual curve. Line segments on the idealized Moment curvature curve shall be located using an iterative graphical procedure that approximately balances the area above and below the curve. Curvature values have been specified for each damage state of the column, first yield moment (DS1), effective yield moment $(D S 2)$, maximum moment $(D S 3)$ and the ultimate curvature of the column when the moment capacity at the moment curvature curve had decreased to $80 \%$ of its maximum attained moment capacity (DS4) (Priestley et al. 1996).

\subsection{Damage fragility}

Equation 4 is used to obtain the damage fragility curves, integrating the demand and damage models derived above for each analyzed bridge. Note that Eq. 4 can be evaluated numerically or, due to the judiciously chosen lognormal form of the variables discussed above, in closed form as

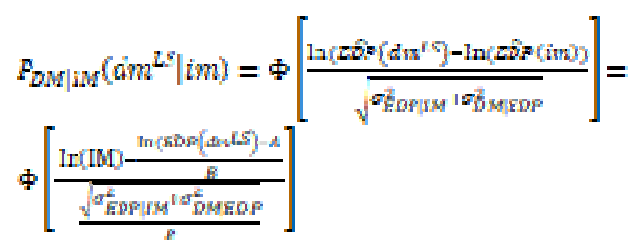

Equation 5 contains two separate sources of uncertainty. The portion attributable to the inherent randomness in the demand $E D P \mid I M$ and damage $D M \mid E D P$ models is termed the aleatory uncertainty. The portion due to lack of knowledge, inadequate mathematical form, missing variables, errors in finite-element analysis, etc. in the demand and damage models is termed epistemic uncertainty. The demand model aleatory uncertainty is available directly from the demand analyses performed. The standard deviation of the demand model can be estimated based on following equation:

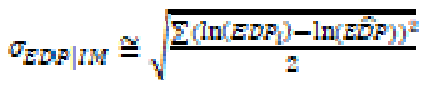

The uncertainty associated with damage model is prescribed in the form of a logarithmic standard deviation or dispersion $\sigma^{2}{ }_{D M \mid E D P}$. The assignment of dispersion is done in a subjective manner due to lack of enough information to quantify it and a dispersion value of 0.35 is adopted across the components and the respective damage states. This value is particularly a good estimate for columns and is consistent with the test results 
documented in the PEER column structural performance database (Berry et al. 2004).

\section{MODELLING AND UNCERTAINTY}

\subsection{Numerical modelling}

Although a more detailed description of the analytical modelling can be found somewhere else (Mangalathu et al. 2016), the general approach is presented herein. 3-D numerical modelling is carried out with the help of the finite element package OpenSees (Mazzoni et al. 2009). The superstructure is modelled using elastic beam column elements. Columns are modelled using fiber-type displacement based beam column elements, foundations are modelled using linear and translational springs, poundings are modelled using contact elements, and shear key is modelled based on experimental work of (Megally et al. 2009). The bearing type used is the elastomeric bearing pad, which is common in concrete bridges. The yield force of the bearing is modelled from an expression developed by (Scharge 1981). Abutment responses comprise earth pressure responses (passive resistance of the backfill) and structural responses (pile resistance or abutment action on spread footing). The passive response of the abutment backwall is simulated using the hyperbolic soil model proposed by (Shamsabadi and Yan 2008) while the response of the piles is simulated using a trilinear material model based on the recommendation of (Mangalathu et al. 2016). The typical configuration of a box girder bridge and associated numerical model of various bridge components are shown in Figure. 1.

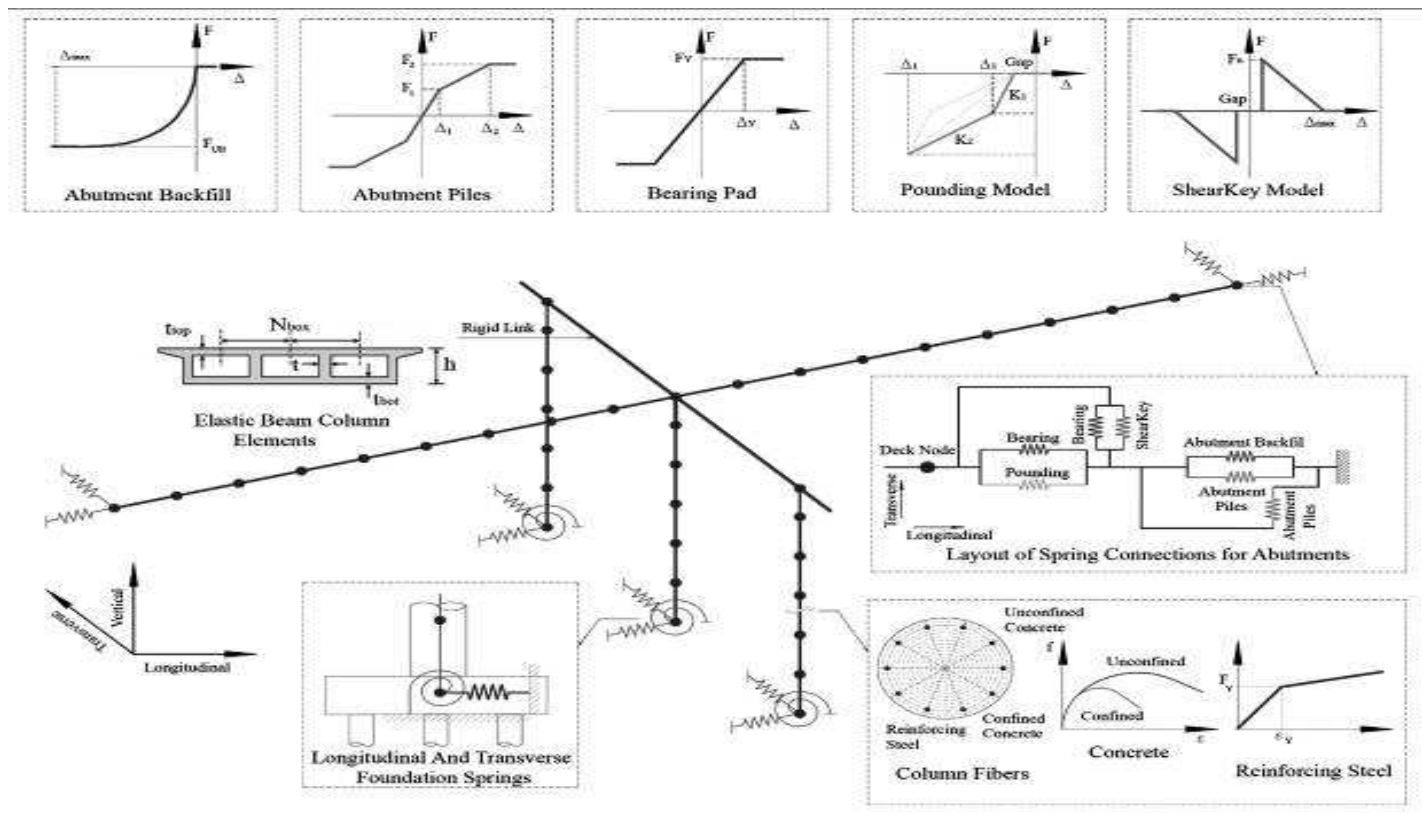

Figure 1. Typical layout of two span bridge model in OpenSEES

In the context of the above, a software was named TSBridge is developed for nonlinear time history analysis and nonlinear static modal pushover analysis. The software is able to show moment curvature of columns, mode shapes, modal pushover of bridge and force displacement of abutment and its components graphically. The software also, is able to calculate strength reduction factors, $\mathrm{R}$ and it can be run for a set of earthquakes consecutively. Based on structure specific properties the structural model is developed and analysed using OpenSees (open source software) and matlab platforms. The software has a wide application to two span concrete bridge inventories.

\subsection{Uncertainty modelling}

The sources of uncertainty evaluated in this study can be generally classified as ground motion, Material and geometric uncertainty. Geometric and material uncertainties, bridge properties whose values were dependent to uncertainty parameters and parameters that were fixed for all of the bridge models with associated distribution are elaborated in Table 4 (Ramanathan et al. 2015). Having identified all the key modelling assumptions and uncertainty distributions of the bridge modelling parameters, the next step is to develop with representative bridge models that can capture the entire range of material and geometric uncertainties. Statistically significant yet nominally identical 1200 bridge models are generated by sampling across the range of parameters (Table 1) using the Latin Hypercube Sampling technique, and 200 bridge are then selected in different ranges of $\mathrm{R}$ randomly so that these bridges cover different $\mathrm{R}$ ranges.

\subsection{Ground motion}

Each bridge configuration was subjected to a suite of 160 ground motions assembled by Baker et al. (2011) in the current study. The suite utilizes the existing high quality next generation attenuation database of recorded ground motions. These motions were not developed as structure-specific or sitespecific, and thus are applicable to many research needs. The Baker set consists of two sets of 120 broadband ground motions having distribution of response spectra associated with moderately large earthquakes at small distances. Further, it 
includes a set of 40 ground motions with strong velocity pulses characteristic of sites experiencing near-fault directivity effects. Summary data for the ground motions in the Baker suite, along with a significant amount of additional information, including the acceleration time history files are available on the website: http://peer.berkeley.edu/transportation/projects/ground-motionstudies-fortransportation-systems.

\section{RESULT}

Eigen value analysis of the bridge models were performed in OpenSEES. A modal pushover analysis is performed on each of the bridge structures simulated in the transverse directions individually. Modal Pushover Analysis is in fact an extension of the standard pushover analysis. According to this procedure, standard pushover analysis is performed for each mode independently, wherein invariant seismic load patterns are defined according to the elastic modal forces. Modal pushover curves, the force-displacement relationship of the SDOF are then plotted. The force-displacement relationship of the SDOF model should be multilinear. Negative post-capping stiffness can also be applied in order to estimate the collapse capacity.

The strength reduction factor $\mathrm{R}$, was obtained as the ratio of maximum base shear that develops in the structure, if it were to remain elastic to the maximum base shear that develops in the structure, at the ductility factor $\mu=\mathrm{u}_{\max } / \mathrm{u}_{\mathrm{y}}$ for a given ground excitation.

The strength reduction factor $\mathrm{R}$ for any bridge is average of the strength reduction factor $\mathrm{R}$ for ground excitations. The $R$ factor is site dependent, as it is a function of the elastic pseudospectral response ordinate $\mathrm{Sa}_{\mathrm{el}}$ at the bridge vibration period. To avoid this dependence, the $\mathrm{R}$ factors were normalized by the elastic pseudospectral acceleration at period $\mathrm{T}=1 s$

$$
\mathrm{R}^{\prime}=\frac{R}{\operatorname{Sa}(\mathrm{T}=1]}
$$

The normalized $\mathrm{R}^{\prime}$ factor is more suitable for comparing the response of the same bridge under different site-specific ground motions. Note that $S_{a}(T=1)$ is often used to define the constant velocity portion of the response spectrum. Furthermore, if site specific response modification factors are not needed, $S_{a}(T=1)$ is usually assumed equal to peak ground acceleration (PGA) (Mackie and Stojadinovic 2004).

The method of probabilistic seismic demand analysis was used (Mackie and Stojadinovic, 2005) to generate relationships between IMs and EDPs, known as probabilistic seismic demand models. Only the PSDMs utilizing the maximum absolute column drift (in transvers direction) was considered in this study. The choice of IM for use with above EDP is limited to the spectral acceleration at a fixed period of $T=1 \mathrm{sec}$. Spectral acceleration $S_{a}(1.0)$, was established as the optimal intensity measure (IM) (Ramanathan et al 2015). A total of $200 \times 160=38400$ Nonlinear Time History Analyses of three dimensional finite element bridge models using OpenSees (Mazzoni et al. 2009) was Performed. A regression analysis is conducted to generate an appropriate PSDM for EDP conditioned on the spectral acceleration $S_{a}(1.0)$. The fragility curve parameters A,B, $\sigma=\sigma_{E D P \mid I M}$ (Eq. 5) for each bridge were calculated by a linear fit to the PSDMs Curves.
Descriptive analyses were conducted using SPSS/WIN 13.0 (SPSS, Inc.) and the path models were analyzed using SPSS AMOS18.0 (SPSS, Inc.). AMOS (Analysis of Moment Structure) is software that is designed specifically for path analysis. Means and standard deviations were evaluated among observed variables (Table 2). The skews of all variables were less than 3 and the coefficients of kurtosis of all variables were less than 8 . Thus, no violation of the assumption of normality was detected.

Table 2. Assessment of normality

\begin{tabular}{|c|c|c|c|c|c|c|}
\hline Variable & $\min$ & $\max$ & skew & c.r. & kurtosis & c.r. \\
\hline PCLS & -2.705 & 3.898 & 0.508 & 2.931 & 1.311 & 3.786 \\
T & 0.49 & 5.72 & 0.872 & 5.032 & -0.187 & -0.541 \\
R' & 7.579 & 16.814 & 1.271 & 7.339 & 0.926 & 2.673 \\
B & 0.69 & 1.32 & -0.505 & -2.917 & 1.464 & 4.225 \\
H. & 1.034 & 6.47 & 0.711 & 4.107 & -0.449 & -1.297 \\
$\mathrm{~A}$ & 0.28 & 3.74 & -0.717 & -4.141 & -0.122 & -0.351 \\
$\sigma$ & 0.271 & 1.455 & 0.927 & 5.352 & 1.447 & 4.177 \\
& & & & & & \\
Multivariate & & & & & 12.065 & 7.6 \\
\hline
\end{tabular}

The Principal component analyses (PCA) method was used for reduce dimensions of column limit state variables CLS1 to CLS4. According to Pedhazur and Schmelkin (1991) the PCA is a method of the multivariate data analysis. The PCA reduces a data set with dimension $m$ to dimension $p$, where $p<m$, by computing the principal components (i.e. new variables) of the original data set with the highest variance by the means of eigenpairs of a corresponding positive semidefinite covariance matrix or correlation matrix. Table 3 and Figure 2 show SPSS output of Principal component PCLS. The factors explain $83.161 \%$ of the total variance.

a. Communalities
\begin{tabular}{|l|c|c|}
\hline & Initial & Extraction \\
\hline CLS1 & 1.000 & .921 \\
CLS2 & 1.000 & .893 \\
CLS3 & 1.000 & .900 \\
CLS4 & 1.000 & .612 \\
\hline
\end{tabular}$\quad$\begin{tabular}{|l|c|}
\hline b. Component Matrix \\
\hline CLS1 & Component 1 \\
\hline CLS3 & .960 \\
CLS4 & .945 \\
.949 \\
\hline
\end{tabular}

C. Total Variance Explained
\begin{tabular}{|c|c|c|c|c|c|c|}
\hline \multirow{3}{*}{} & \multicolumn{3}{|c|}{ Initial Eigenvalues } & \multicolumn{1}{c|}{ Extraction Sums of Squared Loadings } \\
\cline { 2 - 7 } & Total & $\begin{array}{c}\% \text { of } \\
\text { Variance }\end{array}$ & $\begin{array}{c}\text { Cumulative } \\
\%\end{array}$ & Total & $\begin{array}{c}\text { \% of } \\
\text { Variance }\end{array}$ & $\begin{array}{c}\text { Cumulative } \\
\%\end{array}$ \\
\hline 1 & 3.326 & 83.161 & 83.161 & 3.326 & 83.161 & 83.161 \\
2 & .520 & 13.006 & 96.166 & & & \\
3 & .146 & 3.655 & 99.821 & & & \\
4 & .007 & .179 & 100.000 & & & \\
\hline
\end{tabular}

Table 3. SPSS output: Extraction Principal Component PCLS 


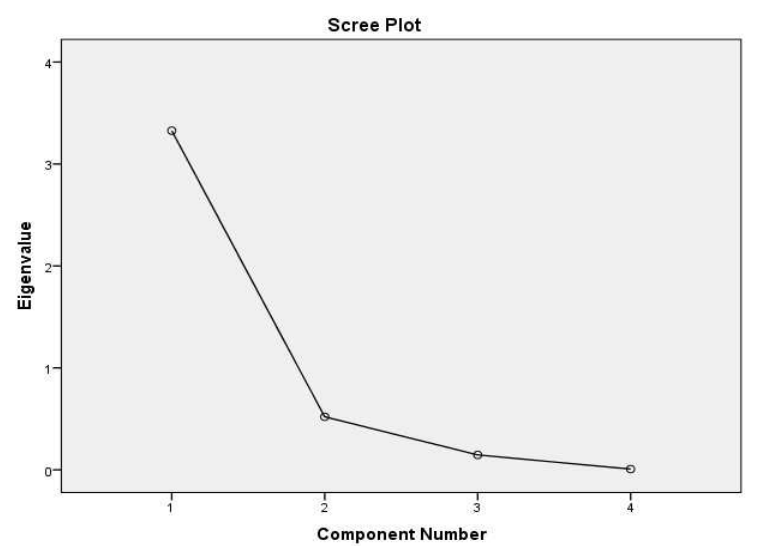

Figure 2. Scree plot of Principal component PCLS Figure 3 shows the hypotheses skeleton model was tested using path analysis within a structural equation model framework. For all constrained parameters in the model, AMOS calculates a modification index. Modification indices indicate how much the chi-square value of a model would drop if the parameter were free instead of constrained (in other words, how much the model fit would improve). Modification indices are in fact chisquare tests for individual equality constraints; high values indicate that the respective parameter constraint is wrong. After the first run, and the Inspecting the unstandardized regression weights, all paths shown not to be significant by the $\mathrm{P}$ value in the output, was step by step deleted from the models. The final model showed in Figure 4 was obtained by eliminating the weak paths from the models. The results of the analysis reduced the Chi-square statistic and DF to 0.913 and 5 respectively. These results were taken as the final statistics, because the results provided by the modification indices were too small to make recognizable differences.

Table 1. Distribution of base model 149 ........ters for concrete box girder two span bridge

\begin{tabular}{|c|c|c|c|c|c|}
\hline \multirow{3}{*}{ Parameter } & \multirow{3}{*}{$\begin{array}{l}\text { Distribution } \\
\text { type }\end{array}$} & \multicolumn{2}{|c|}{ Distribution } & \multirow{3}{*}{ Units } & \multirow{3}{*}{ dependency } \\
\hline & & \multicolumn{2}{|c|}{ parameters } & & \\
\hline & & $\mathrm{a}$ & $\mathrm{b}$ & & \\
\hline Column height & Normal & Mean $=5.48$ & $\mathrm{STD}=1.12$ & $\mathrm{~m}$ & $\mathrm{U}$ \\
\hline Longitudinal reinforcement ratio & Uniform & $\operatorname{Min}=1 \%$ & $\operatorname{Max}=3.5 \%$ & & $\mathrm{U}$ \\
\hline Transverse reinforcement ratio & Uniform & Min $=0.4 \%$ & $\operatorname{Max}=1.7 \%$ & & $\mathrm{U}$ \\
\hline Number of columns per bent & & $1,2,3,4,5$ & & & D (deck width) \\
\hline Diameter & & 4,5 & & $\mathrm{~m}$ & $\mathrm{D}$ (number of column) \\
\hline Span length & Normal & Mean $=35.0$ & $\mathrm{STD}=12.34$ & $\mathrm{~m}$ & $\mathrm{U}$ \\
\hline Deck width & Normal & Mean $=20.48$ & $\mathrm{STD}=12.86$ & $\mathrm{~m}$ & $\mathrm{U}$ \\
\hline Number of boxes & & $\operatorname{Min}=3$ & $\operatorname{Max}=15$ & & D (deck width) \\
\hline Total superstructure depth & & & & $\mathrm{m}$ & D (bridge span length) \\
\hline Top flange depth & & Min $=17.8$ & $\operatorname{Max}=28.0$ & $\mathrm{Cm}$ & $\mathrm{D}$ (number of boxes) \\
\hline Bottom flange depth & & 17.8 & & $\mathrm{Cm}$ & $\mathrm{F}$ \\
\hline Wall thickness & & 30.5 & & $\mathrm{Cm}$ & $\mathrm{F}$ \\
\hline Translational spring stiffness & Normal & Mean $=1.4 \mathrm{e} 5$ & $\mathrm{STD}=1.05 \mathrm{e} 5$ & $\mathrm{KN} / \mathrm{m}$ & $\mathrm{U}$ \\
\hline Rotational spring stiffness & Normal & Mean $=1.14 \mathrm{e} 10$ & $\mathrm{STD}=1.75 \mathrm{e} 9$ & $\mathrm{KN} / \mathrm{m} / \mathrm{rad}$ & $\mathrm{U}$ (for multi column $=0$ ) \\
\hline Shear modulus of bearing & Uniform & $\operatorname{Min}=5.5 \mathrm{e} 2$ & $\operatorname{Max}=1.7 \mathrm{e} 3$ & $\mathrm{MPa}$ & $\mathrm{U}$ \\
\hline Bearing pad coefficient of friction & & & & & $\mathrm{D}$ (deck weight) \\
\hline Number of Bearing pads & & & & & $\begin{array}{c}\mathrm{D} \text { (deck weight, Shear } \\
\text { modulus) }\end{array}$ \\
\hline Abutment backwall height & Uniform & $\operatorname{Min}=1.0$ & $\operatorname{Max}=2.6$ & $\mathrm{~m}$ & $\mathrm{U}$ \\
\hline Angle of incidence of earthquake & & 0 or 90 & & degree & $\mathrm{U}$ \\
\hline Soil stiffness & & 4380 or 8760 & & $\mathrm{KN} / \mathrm{m}$ & $\mathrm{U}$ \\
\hline
\end{tabular}




\begin{tabular}{|c|c|c|c|c|c|}
\hline Pile stiffness & Lognormal & Mean $=1.4 \mathrm{e} 4$ & $\mathrm{STD}=52.5$ & $\mathrm{KN} / \mathrm{m}$ & $\mathrm{U}$ \\
\hline Gap at abutment & Uniform & $\operatorname{Min}=0$ & $\mathrm{Max}=5.08$ & $\mathrm{Cm}$ & $\mathrm{U}$ \\
\hline Number of abutment piles & & & & & D (bridge width) \\
\hline Gap at shear key & Uniform & $\operatorname{Min}=0$ & $\mathrm{Max}=5.08$ & $\mathrm{Cm}$ & $\mathrm{U}$ \\
\hline Shearkey capacity & & & & $\mathrm{KN}$ & D (shear capacity of piles) \\
\hline Concrete strength & Normal & Mean $=34.5$ & $\mathrm{STD}=4.3$ & $\mathrm{MPa}$ & $\mathrm{U}$ \\
\hline Steel strength & Lognormal & Mean=336.4 & $\mathrm{STD}=0.75$ & $\mathrm{MPa}$ & $\mathrm{U}$ \\
\hline Damping coefficient & Normal & Mean $=0.045$ & $\mathrm{STD}=0.0125$ & & $\mathrm{U}$ \\
\hline Additional mass coefficient & Uniform & $\operatorname{Min}=0.1$ & $\operatorname{Max}=0.4$ & & $\mathrm{U}$ \\
\hline
\end{tabular}

*U: Uncertain, D: dependent, F: Fix, STD: Standard deviation

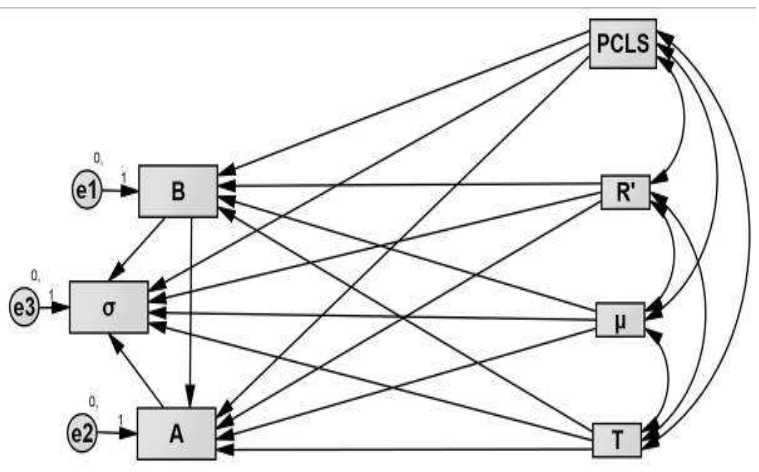

Figure 3. The hypotheses skeleton model

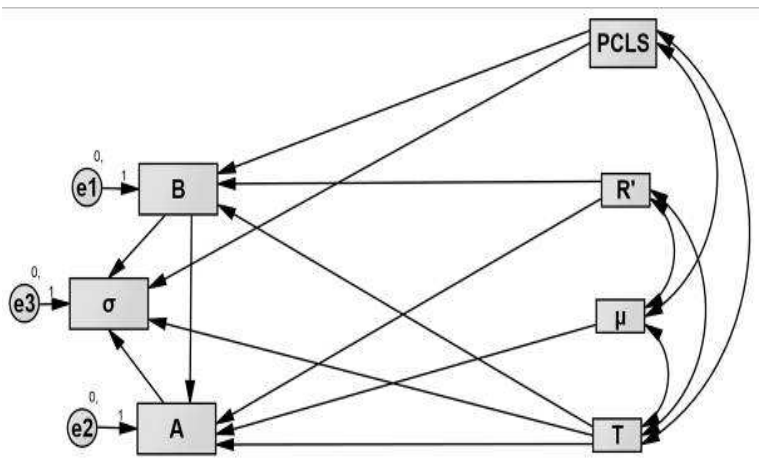

Figure 4. The final hypotheses model

The results of the path analysis with the standardized regression coefficients were presented below in Figure 5. Table 4 list the estimated path coefficients that minimize the difference between observed and model along with their corresponding standard errors, critical ratios, and p-values. Tables 5-9 show the standardized total, direct and indirect relationships so that the factors effect on A with 5 variables were B, R', T, $\mu$ and PCLS.

There is a significant positive correlation between $\mathrm{A}$ and T. T had a direct effect to A and was 0.732 and had indirect effect through B which was 0.048 ; total effect was 0.78 . Similarly, there is a positive correlation between B and A. with a direct to A was 0.439 , and had not indirect effect. There is a negative correlation between A and R'. R' had a direct effect to A and was -0.204 and had indirect effect through $B$. which was 0.119 ; total effect was -0.086 . The factors affecting B with 3 variable were R', PCLS and T. PCLS, T and R' had a direct effect to B were $-0.298,-0.109$ and 0.27 respectively and had no indirect effect.

The factors PCLS, T, R', B , $\mu$ and A also affects $\sigma$ with direct, indirect, total effects which were listed in Tables 5-9.

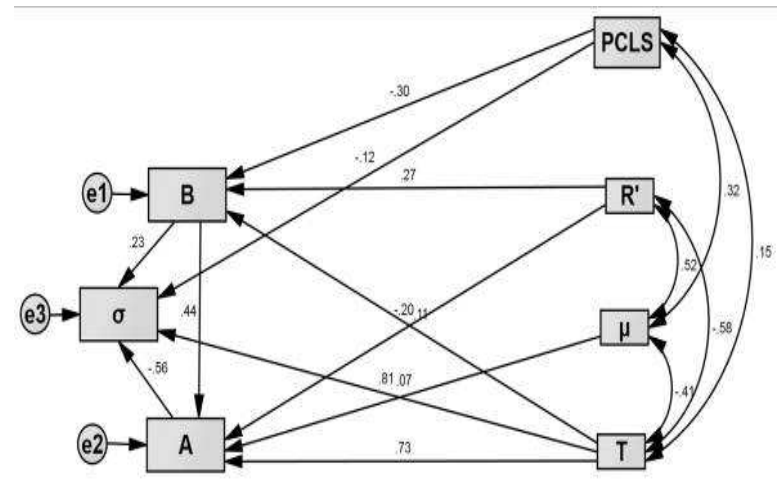

Figure 5. Standardized direct effects of hypotheses model

Goodness of fit of the final model was assessed by chi-square test and the goodness of fit indices, such as Root Mean Square Error of Approximation (RMSEA) and comparative fit index (CFI). Selected goodness-of-fit statistics related to the hypothesized model was presented in Table 10. This model had a good fit with a chi-square $=0.913(\mathrm{df}=5), \mathrm{RMSEA}=0.000$, and $\mathrm{a}$ CFI $=1.000$.

Table 4. Regression weights

\begin{tabular}{|ccc|c|c|c|c|}
\hline & & & Estimate & S.E. & C.R. & P \\
\hline B & $\leftarrow$ & PCLS & -0.031 & 0.007 & -4.422 & $* * *$ \\
$\mathrm{~B}$ & & $\mathrm{R}^{\prime}$ & 0.013 & 0.004 & 3.323 & $* * *$ \\
\hline
\end{tabular}




\begin{tabular}{|ccc|c|c|c|c|}
\hline $\mathrm{B}$ & $\leftarrow$ & $\mathrm{T}$ & 0.008 & 0.006 & 1.33 & 0.083 \\
$\mathrm{~A}$ & $\leftarrow$ & $\mathrm{B}$ & 3.238 & 0.247 & 13.127 & $* * *$ \\
$\mathrm{~A}$ & $\leftarrow$ & $\mathrm{T}$ & 0.408 & 0.022 & 18.322 & $* * *$ \\
$\mathrm{~A}$ & $\leftarrow$ & $\mathrm{R}^{\prime}$ & -0.072 & 0.016 & -4.651 & $* * *$ \\
$\mathrm{~A}$ & $\leftarrow$ & $\boldsymbol{\mu}$ & 0.04 & 0.021 & 1.933 & 0.053 \\
$\sigma$ & $\leftarrow$ & $\mathrm{B}$ & 0.461 & 0.175 & 2.639 & 0.008 \\
$\sigma$ & $\leftarrow$ & $\mathrm{T}$ & 0.125 & 0.019 & 6.439 & $* * *$ \\
$\sigma$ & $\leftarrow$ & $\mathrm{A}$ & -0.155 & 0.037 & -4.216 & $* * *$ \\
$\sigma$ & $\leftarrow$ & $\mathrm{PCLS}$ & -0.025 & 0.014 & -1.766 & 0.077 \\
\hline
\end{tabular}

Table 5. Standardized regression weights

\begin{tabular}{|ccc|r|}
\hline & & & \\
\hline B & $\leftarrow$ & PCLS & -0.298 \\
B & $\leftarrow$ & $\mathrm{R}^{\prime}$ & 0.27 \\
B & $\leftarrow$ & $\mathrm{T}$ & 0.109 \\
$\mathrm{~A}$ & $\leftarrow$ & $\mathrm{B}$ & 0.439 \\
$\mathrm{~A}$ & $\leftarrow$ & $\mathrm{T}$ & 0.732 \\
$\mathrm{~A}$ & $\leftarrow$ & $\mathrm{R}^{\prime}$ & -0.204 \\
$\mathrm{~A}$ & $\leftarrow$ & $\mathbf{H}$ & 0.075 \\
$\sigma$ & $\leftarrow$ & $\mathrm{B}$ & 0.225 \\
$\sigma$ & $\leftarrow$ & $\mathrm{T}$ & 0.808 \\
$\sigma$ & $\leftarrow$ & $\mathrm{A}$ & -0.558 \\
$\sigma$ & $\leftarrow$ & PCLS & -0.117 \\
& & &
\end{tabular}

Table 6. Correlations

\begin{tabular}{|ccc|r|}
\hline & & & Estimate \\
\hline $\mathrm{R}^{\prime}$ & $\leftrightarrow$ & $\mathrm{T}$ & -0.575 \\
$\mathrm{~T}$ & $\leftrightarrow$ & PCLS & 0.147 \\
$\boldsymbol{\mu}$ & $\leftrightarrow$ & $\mathrm{R}^{\prime}$ & 0.52 \\
$\boldsymbol{\mu}$ & $\leftrightarrow$ & $\mathrm{T}$ & -0.41 \\
$\boldsymbol{\mu}$ & $\leftrightarrow$ & PCLS & 0.322 \\
\hline
\end{tabular}

Table 7. Standardized total effects - estimates

\begin{tabular}{|c|cccccc|}
\hline & PCLS & T & $\mathrm{R}^{\prime}$ & $\mathrm{B}$ & $\mathbf{\mu}$ & $\mathrm{A}$ \\
\hline $\mathrm{B}$ & -0.298 & 0.109 & 0.27 & 0 & 0 & 0 \\
$\mathrm{~A}$ & -0.131 & 0.78 & -0.086 & 0.439 & 0.075 & 0 \\
$\sigma$ & -0.111 & 0.397 & 0.109 & -0.02 & -0.042 & -0.558 \\
\hline
\end{tabular}

Table 8. Standardized direct effects - Estimates

\begin{tabular}{|c|cccccc|}
\hline & PCLS & T & R' $^{\prime}$ & B & $\mu$ & A \\
\hline B & -0.298 & 0.109 & 0.27 & 0 & 0 & 0 \\
A & 0 & 0.732 & -0.204 & 0.439 & 0.075 & 0 \\
$\sigma$ & -0.117 & 0.808 & 0 & 0.225 & 0 & -0.558 \\
\hline
\end{tabular}

\section{CONCLUSIONS}

This paper presents a new method to analyze the effect of R', $\mu$, $\mathrm{T}$ on the fragility curve parameters $\mathrm{A}, \mathrm{B}, \sigma$ using the path analysis technique. The major advantage of the path analysis method is its ability to analysis the relationship between dependent variables as well as between independent variables and dependent variables from one time analysis.

The method is demonstrated through studies of the two spans reinforced concrete highway bridge class. A set of detailed three-dimensional bridge models accounting for material, geometric, and system uncertainties is simulated in OpenSees and used the probabilistic seismic demand models developed based on the NLTHAs. For the application of path analysis, R', $\mu, \mathrm{T}$ bridge attributes are considered.

The overall findings of the study suggest that $\mathrm{T}$ has the most total positive effect on A including a direct effect 0.732 and a indirect effect 0.048 , while $\mathrm{R}^{\prime}$ has the most total positive effect on $\mathrm{B}$ including a direct effect 0.27 and did not has a indirect effect on B. T and A have the most total positive and negative effects on $\sigma$ respectively.

Table 9. Standardized indirect effects - estimates

\begin{tabular}{|c|cccccc|}
\hline & PCLS & T & $\mathrm{R}^{\prime}$ & $\mathrm{B}$ & $\mathrm{\mu}$ & $\mathrm{A}$ \\
\hline B & 0 & 0 & 0 & 0 & 0 & 0 \\
$\mathrm{~A}$ & -0.131 & 0.048 & 0.119 & 0 & 0 & 0 \\
$\sigma$ & 0.006 & -0.411 & 0.109 & -0.245 & -0.042 & 0 \\
\hline
\end{tabular}

Table 10. Goodness of fit of the final model

\begin{tabular}{|c|c|c|c|c|c|}
\hline \multicolumn{6}{|c|}{ a. } \\
\hline Model & NPAR & CMIN & DF & P & CMIN/DF \\
Main & 30 & 1.503 & 5 & 0.913 & 0.301 \\
\hline
\end{tabular}

\begin{tabular}{|c|c|c|c|c|c|}
\hline \multicolumn{6}{|c|}{ b. $\quad$ Baseline comparisons } \\
\hline \multirow{2}{*}{ Model } & NFI & RFI & IFI & TLI & CFI \\
& Delta1 & rho1 & Delta2 & rho2 & \\
Main & 0.997 & 0.989 & 1.006 & 1.026 & 1 \\
\hline
\end{tabular}




\begin{tabular}{|c|c|c|c|c|}
\hline Model & RMSEA & LO 90 & HI 90 & PCLOSE \\
Main & 0 & 0 & 0.037 & 0.968 \\
\hline
\end{tabular}

\section{References:}

Alwin, D.F., and Hauser, R.M., 1975. The decomposition of effects in path analysis. American sociological review, pp. 3747.

Baker, J. W., and Allin Cornell, C., 2005. A vector-valued ground motion intensity measure consisting of spectral acceleration and epsilon. Earthquake Engineering \& Structural Dynamics, 34(10), pp. 1193-1217.

Bentler, P. M. 1990. Comparative fit indexes in structural models. Psychological bulletin, 107(2), 238.

Berry, M., Parrish, M., and Eberhard, M., 2004. PEER Structural Performance Database, User's Manual (Version 1.0). University of California, Berkeley.

Browne, M. W., and Cudeck, R. 1993. Alternative ways of assessing model fit. Sage focus editions, 154, pp. 136-136.

Celik, OC., and Ellingwood, BR., 2010. Seismic fragilities for non-ductile reinforced concrete frames-Role of aleatoric and epistemic uncertainties. Structural Safety, 32, pp. 1-12

Choi, E., DesRoches, R., and Nielson, B., 2004. Seismic fragility of typical bridges in moderate seismic zones. Engineering Structures, 26, pp. 187-199.

Cornell, CA. and Krawinkler, H., 2000. Progress and challenges in seismic performance assessment. PEER center news, 3, pp. 13.

DesRoches, R., Padgett, J., Ramanathan, K. and Dukes, J. 2012. Feasibility studies for improving Caltrans bridge fragility relationships No. CA12-1775.

Jeong, S-H., and Elnashai, AS., 2007. Probabilistic fragility analysis parameterized by fundamental response quantities. Engineering Structures, 29, pp. 1238-1251.

Kennedy, R. P., and Ravindra, M. K., 1984. Seismic fragilities for nuclear power plant risk studies. Nuclear Engineering and Design, 79(1), pp. 47-68.

Kircher, C. A., Whitman, R. V. and Holmes, W. T., 2006. HAZUS earthquake loss estimation methods. Natural Hazards Review, 7(2), pp. 45-59.

Land, K. C. 1969. Principles of path analysis. Sociological methodology, 1: 3-37.

Luco N., and Cornell, CA., 2007. Structure-specific scalar intensity measures for near-source and ordinary earthquake ground motions. Earthquake Spectra, 23, pp. 357-392.

Mackie, K., and Stojadinovic, B., 2004. Improving probabilistic seismic demand models through refined intensity measures. In: Proc. 13 ${ }^{\text {th }}$ World Conf. Earthquake Eng. Int. Assoc. for Earthquake Eng. Japan, August 2004.
Mackie, KR., and Stojadinovic, B., 2005. Fragility basis for California highway overpass bridge seismic decision making. Pacific Earthquake Engineering Research Center, College of Engineering, University of California, Berkeley.

Kadysiewski, S. and Mosalam, K.M., 2009. Modeling of unreinforced masonry infill walls considering in-plane and outof-plane interaction (Vol. 70). Berkeley, California, USA: Pacific Earthquake Engineering Research Center.

McKay, MD., Beckman, RJ. and Conover, WJ., 2000. A comparison of three methods for selecting values of input variables in the analysis of output from a computer code. Technometrics, 42, pp. 55-61.

Megally, S., Veletzos, MJ., Burnell, K., Restrepo, JI. and Seible, F., 2009. Seismic performance of precast concrete segmental bridges: Summary of experimental research on segment-to-segment joints. PCI journal, 54(2).

Nielson, B. G., 2005. Analytical fragility curves for highway bridges in moderate seismic zones. $\mathrm{PhD}$ Thesis., Georgia Institute of Technology,

Padgett, JE., Nielson, BG. and DesRoches, R. 2008. Selection of optimal intensity measures in probabilistic seismic demand models of highway bridge portfolios. Earthquake Engineering \& Structural Dynamics, 37, pp. 711-725.

Pedhazur, E. J., and Pedhazur Schmelkin, L. 1991. Exploratory factor analysis. Measurement, design and analysis: An integrated approach, pp. 590-630.

Priestley, MN, Seible, F., and Calvi, GM., 1996. Seismic design and retrofit of bridges. John Wiley \& Sons.

Ramanathan, K., DesRoches, R., and Padgett, J., 2010. Analytical fragility curves for multispan continuous steel girder bridges in moderate seismic zones. Transportation Research Record: Journal of the Transportation Research Board, pp. 173-182.

Ramanathan, K., Padgett, JE., and DesRoches, R., 2015. Temporal evolution of seismic fragility curves for concrete boxgirder bridges in California. Engineering Structures, 97, pp. 2946.

Scharge, L., 1981. Anchoring of bearings by friction, joint sealing and bearing systems for concrete structures. In: World congress on joints and bearings (Vol. 1).

Shamsabadi, A., Yan, L. 2008. Closed-form force-displacement backbone curves for bridge abutment-backfill systems. In: Geotechnical Earthquake. Engineering and Soil Dynamics, IV: pp. 1-10.

Shome, N., 1999. Probabilistic seismic demand analysis of nonlinear structures. Stanford University.

Singhal, A., and Kiremidjian, A. S., 1996. Method for probabilistic evaluation of seismic structural damage. Journal of Structural Engineering, 122(12), pp. 1459-1467. 
Straub, D., and Der Kiureghian, A., 2008. Improved seismic fragility modeling from empirical data. Structural safety, 30(4): pp. 320-336.

Wright, S., 1921. Correlation and causation. Journal of agricultural research, 20(7), pp. 557-585. 